\title{
Design and Manufacture of 1kW Wind Turbine Blades
}

\section{Fana Filli*, Anwar M. Mahmud, Mulu Bayray, Meseret Tesfay and Petros Gebray} School of Mechanical Engineering, Ethiopian Institute of Technology-Mekelle, Mekelle University, Ethiopia (*fana.filli@mu.edu.et).

\begin{abstract}
To meet sustainable development goals and address concerns on climate change, much of the world's energy demand is expected to be delivered from clean alternative energy sources. Smallscale wind turbines have proven to be applicable for off-grid electrification. The objective of this study is to present the details on the design and manufacture of a $1 \mathrm{~kW}$ wind turbine blade for specified conditions. Blade element moment theory is adopted in the design of the geometry of the blade. Accordingly, the aerodynamic analysis on NACA 64A410 airfoil resulted in a blade radius of $1.95 \mathrm{~m}$, an overall twist angle of $31^{\circ}$, and a gradually tapering chord length of $0.062 \mathrm{~m}$ at the root and $0.247 \mathrm{~m}$ at the tip of the blade. Then, the wind turbine blades are manufactured from fiberglass (mat350g), resin, catalyst, and gelcoat. Experimental results reveal the wind turbine blades started producing power at a cut-in wind speed of $3 \mathrm{~m} / \mathrm{s}$. The maximum power achieved during the testing process was $900 \mathrm{~W}$ at a hub wind velocity of $9 \mathrm{~m} / \mathrm{s}$. This is lower than the expected $1000 \mathrm{~W}$ theoretical power output due to not perfect workmanship in the manufacture of the wind turbine blades. This study will help in building local manufacturing facilities and enhance rural electrification through off-grid technologies.
\end{abstract}

Keywords: Wind turbine blade, Local manufacturing, Alternative energy, Wind energy, Ethiopia.

\section{INTRODUCTION}

To meet sustainable development goals and address concerns on climate change, much of the world energy demand is expected to be delivered from clean alternative energy sources. Renewable energy sources, such as solar and wind energy, have gained popularity in the last few decades. Small and medium scale wind turbine technologies are preferred for distributed generation especially in meeting the energy demand from remote areas which cannot be supplied from grid electricity. Developed countries are currently manufacturing and supplying small scale wind turbines (ARE, 2012). In Ethiopia, such technology and manufacturing facilities are yet to be established. Most of the energy technology hardware is imported, which requires high foreign exchange (Afanador et al., 2016). Growth and transformation plan II (GTP-II) (2015/16 - 2019/20) envisages rapid and sustainable growth through advanced manufacturing and quality production (NPC, 2016). Development of the manufacturing sector offers creation of job opportunities. 
This paper deals with the design and development of small scale wind turbine blades. Three wind turbine blades capable of generating $1 \mathrm{~kW}$ wind power are designed, manufactured from locally available materials and tested in Mekelle University, Ethiopia. The outcome of the study is presented below under different sections. Section 2 highlights on the rationale for building local manufacturing facilities to realize small scale turbine blades and associated environmental and economic benefits. Section 3 provides detail on material selection and manufacturing process. Section 5 presents the detail on manufacturing, whereas the resting of the realized blade is described in section 6. Successful testing of wind turbine blades confirms the design and the adequacy of the selected material. It is noted that the wind turbine is capable of producing $900 \mathrm{~W}$ power at an average velocity of $9 \mathrm{~m} / \mathrm{s}$. The designed $1 \mathrm{~kW}$ wind turbine blade can be utilized for small scale applications including on or off-grid residences, telecom towers, rural schools and clinics and other purposes that require energy where there is no electric grid.

\section{DEVELOPMENT OF SMALL SCALE WIND TURBINE BLADES}

\subsection{Small Scale Wind in Developing Countries}

Rising energy demands due to economic growth, industrialization, urbanization and population growth in developing countries (Keho, 2016) and environmental concerns over fossil fuels in the developed countries has necessitated the shift to an alternative energy technologies such as wind and solar energies (REN21, 2018). Wind energy has emerged as a cost effective option for offgrid electrification that attracted the attention of many countries (Qurashi and Hussain, 2005). However, in recent years, despite their capability to produce cost-effective electricity and environmental advantages, small and medium wind turbines have been left out as an option by the policy makers (Marcus, 2013). In the developing countries, this is due to lack of strong supporting policies for small wind technologies (WWEA, 2017). This is partly due to the gap in the existing knowledge and level of experience by the stakeholders in the implementation of energy- related initiatives (Rolland, 2013). Therefore, while small scale wind energy can be a suitable choice for off-grid electrification, there is a need for integrated effort to realize its benefits in developing countries (Foster, 2011).

Therefore, it is essential to produce innovative interventions to realize the sustainable deployment of renewable energy technologies. Interventions could range from developing 
strategies for access to modern energy services to demonstrating local capacity in the design, development and testing of alternative energy technologies.

\subsection{Rationale for Small Scale Wind Turbine Manufacturing in Ethiopia}

Compared to developing countries, Ethiopia is undergoing rapid socio-economic growth and hence the demand for and reliable electric power is ever increasing. On the other hand, an overwhelming majority of Ethiopians live without access to modern energy services largely dominated by the use of biomass for heating and lighting (Mulugetta, 2008). Despite the expansion of grid to urban areas, many rural communities in off-grid areas are unable to grow economically and develop like other communities which have access to grid electricity. According to United Nations (UN) sustainable development goals, the growth and prosperity is determined by the cost and availability of energy. The government of Ethiopia also recognizes the need for extensive investments in large scale energy developments for socioeconomic development. All the initiatives of the government such as the Climate-Resilient Green Economy (CRGE) and Growth and Transformation Plan II (GTP-II) (2015/16 - 2019/20) are geared towards the achievement of global sustainable goals. According to the Ethiopian National Electrification Program (NEP), the country plans to meet the UN universal access to electricity through grid (65\%) and off-grid (35\%) mechanisms by 2025 (World Bank, 2018).

The environmental policy of Ethiopia gives due place to alternative energy sources in the energy development in future. Particularly, the policy guidelines for development and management of the energy sources, for example, the development of indigenous energy sources to acquire, develop, test and disseminate appropriate and improved energy use technologies (Dalelo, 2003). In this regard, a number of outstanding research outputs have been achieved in the dissemination of improved cooking stoves and charcoal kilns. However, except with few solar energy technologies for solar water heating system, solar cookers, crop drying and food processing, the local design and development of wind energy technologies is non-existent.

Due to the inefficient technology transfer, and under developed industry for manufacturing, most of the energy technology hardware is imported, which leads to high foreign exchange spending (Afanador et al., 2016). According to a study conducted by Sessarego and Wood (2015), most developing countries must import PV equipment, whereas there is scope for significant local manufacture of many wind turbine components, often using indigenous and sustainable materials. 
Growth and Transformation Plan II (GTP-II) (2015/16 - 2019/20) envisages rapid and sustainable growth through enhanced manufacturing and quality production (NPC, 2016). Besides, studies have shown that Ethiopia is a country with great potential for wind energy (Rolland, 2013).

Hence, small scale wind turbine can then be used to meet the energy demands of residential, farm, small business, school or campus, hospitals and telecom facilities etc.

\subsection{Design and development of small scale wind turbine blades}

The design of wind turbine blades is made in such a way it extracts maximum amount of energy from the incoming wind flow. For this, there is an optimum geometry for the structure of a wind turbine blades. The cross-sectional shape of blades in modern wind turbines is made of an airfoil shape. The development of airfoils specifically for horizontal axis wind turbines began in the early 1984 at the US National Renewable Energy Laboratory (NREL) (Tangler and Somers, 1995). The purpose of selection of shape is to identify the airfoil with the characteristics that best fits for the good performance of wind turbine blade. Preliminarily, airfoil with high maximum lift to drag coefficient, insensitive to roughness and airfoil with negligible drag and tip losses are applicable for wind turbine blade. The selection of airfoil is characterized by the shape, thickness, camber line, lift per drag ratio and Reynolds number because, these parameters influence the aerodynamic properties of the airfoil (Thumthae, 2015). Based on these properties, a set of airfoils have been designed for wind turbines characterized by the power output and aerodynamic interaction. NACA 6- series airfoil is used in many modern horizontal axis wind turbines (Mohammadi et al., 2015).

The cost and reliability of a wind turbine blade depends on the type of material and the manufacturing process and technology. Early wind turbine blades were made of steel (Mishnaevsky et al., 2017). The progress in science and technology has resulted in using composite materials in modern wind turbine blades. Hence, glass fibers, carbon fibers and their combinations are used in majority of blades manufactured. The quality of which is not only dependent on the type of material used but also on the consistency of fiber surface treatment and manufacturing process (Prabhakaran et al., 2011).

\section{MATERIALS AND MANUFACTURING METHODS}

The process of wind turbine blade design and manufacture consists mainly of determining the blade geometry, material selection, and blade manufacture (Wood, 2011). The design and manufacture method of the $1 \mathrm{~kW}$ wind turbine blades is illustrated in three stages. First, the 
aerodynamic interaction of wind and blade was analyzed to determine the main geometry of the blade. Next, the mold was produced from wood laminates and bars with careful consideration of the main features such as chord length and twist. Finally, the turbine blade was made of two halves of independently made fiberglass structures in their respective molds. Then, the two halves of the blade are glued together with a central wooden support structure placed between them. The external surfaces of the blade are then carefully treated and polished to produce a smooth surface for efficient conversion of wind flow to kinetic energy.

\subsection{Design}

Blade element momentum (BEM) theory is one of the most widely used methods for design of wind turbine blades (Hansen, 2017). Accordingly, the BEM method was adopted to design the main features of the wind turbine blade.

The BEM method is based on the following assumptions (Ingram, 2011).

i. Steady-state situation: The wind is absolutely constant or it changes slowly that the flow around the blade can be said to be in a steady-state situation.

ii. The wind speed is uniform over the whole turbine.

iii. There is no flow in the radial direction of the blade and each blade element is totally independent of the others.

iv. The blade has a perfect stiffness and does not flex or bend.

\subsection{Blades}

The design of wind turbine blades is made in such a way it extracts maximum amount of energy from an incoming wind flow. Several studies have reported that there is an optimum geometry of a wind turbine blade for maximum power extraction (Thumthae, 2015; Richard and Crossley, 2012a \& 2012b; Prombut, 2010). Therefore, depending on the purpose and optimization between power production and manufacturing, a number of airfoil shapes have been designed. The NACA 6- series airfoil have therefore been used in many modern horizontal axis wind turbines (Mohammadi et al., 2015).

The design of wind turbine blades is determined by a set of variables such as wind velocity, tip speed ratio, assumed efficiency, number of blades, blade profile, angle of attack, lift and drag coefficients, and density of air (Richard and Crossley, 2012a \& 2012b). Of these parameter, the most important is the tip speed ratio that determines the application of the wind turbine blade. For example, low tip speed ratio is considered for high torque and low rotational speed applicable for 
water pumping and wind mills. Higher tip speed ratio are considered in wind turbine for electric power production (Richard and Crossley, 2012a \& 2012b). The aerodynamic design of wind turbine blades is made through an optimization of empirical equations (Hau, 2006). Therefore, with certain ranges of assumptions on efficiency of wind turbines and local wind speed at which the turbine is designed, the diameter of the blade for a given power output can be calculated. Finally, all the geometrical features of the wind turbine blade are calculated and an optimum blade shape is determined

\subsection{Mold}

A mold having the exact imprint of the blade was produced from low-cost and rigid structure to help maintain the shape of the blades. For preparation of the mold, the airfoil shapes of the blade are first printed on a paper and inscribed on a plywood template. Depending on the twist angle for each section and the chord length of the blade, the plywood templates are prepared. The blade profile templates are polished to the desired shape and stack next to each other sequentially at a predefined distance. Finally, the structure of the mold is cut into upper and lowers half sections and laminated with thin-film of fiber glass layers and resin.

\section{BLADE DESIGN}

\subsection{The Forces on Blade Element}

The forces on a wind turbine blade can be expressed in terms of the geometry of the blade and wind flow. The geometry of the wind turbine blade determines the angle of attack, the lift and drag coefficients depending on the nature of the airfoil profile. Figure 1 shows the leading edge is directed against the relative velocity of the incoming wind at an angle alpha ( $\alpha$ angle of attack). The analysis of the wind flow on the airfoil gives rise to the lift forces and drag forces. The developments in the characteristics of the blade and wind interaction are discussed below.

\subsection{Blade Airfoil Selection}

NACA 64A410 airfoil is selected from NACA 6-series airfoil which are widely used in small scale wind turbine blades (Mohammadi et al., 2015). NACA 64A410 airfoil has a maximum thickness $10 \%$ of the chord length positioned at $39 \%$ of the chord length. To make the manufacturing of the wind turbine blades easy, the trailing edge of the blade is slightly made straight while maintaining the general feature of the airfoil. Table 1 gives the design parameters for optimum design of the wind turbine blade. 
Figure 1. Forces on blade element.

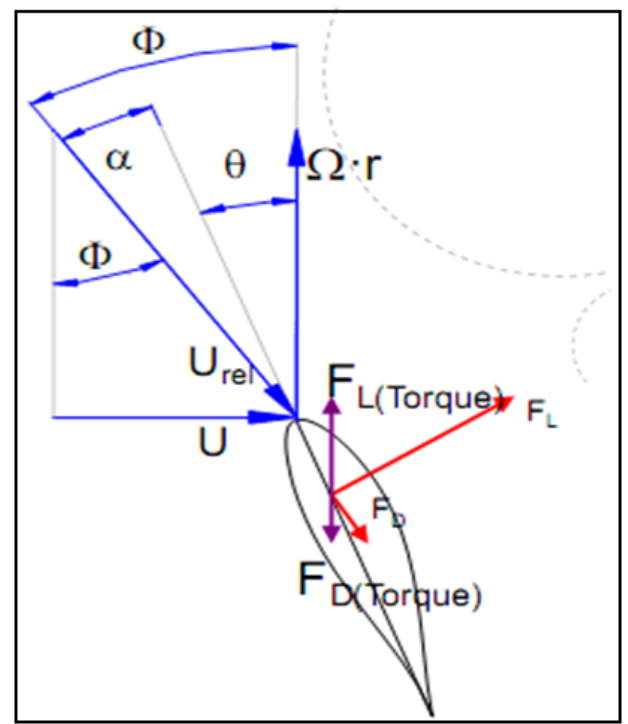

Table 1. Blade design parameters.

\begin{tabular}{|lll|}
\hline \multicolumn{3}{|c|}{ Design parameters } \\
\hline Power output & $\mathrm{P}$ & $1000[\mathrm{~W}]$ \\
\hline Wind velocity & $\mathrm{U}$ & $7[\mathrm{~m} / \mathrm{s}]$ \\
\hline Tip speed ratio & TSR & 7 \\
\hline Assumed efficiency & $\mathrm{H}$ & 0.4 \\
\hline Number of blades & $\mathrm{Z}$ & 3 \\
\hline Blade profile & $\mathrm{NACA}$ & $64 \mathrm{~A} 410$ \\
\hline Angle of attack & $\mathrm{A}$ & 5 \\
\hline Lift coefficient & $\mathrm{C}_{1}$ & 0.58 \\
\hline Drag coefficient & $\mathrm{C}_{\mathrm{d}}$ & 0.015 \\
\hline Density of wind & $\mathrm{P}$ & $1.225\left[\mathrm{~kg} / \mathrm{m}^{3}\right]$ \\
\hline
\end{tabular}

\subsection{Calculation and Analysis}

\subsubsection{Radius of the Turbine}

First, the radius is calculated using the expression for the power output of the turbine (equation 1) by assuming the design turbine efficiency of $40 \%$ (since the practical efficiency that can be attained in modern wind turbine is in the range of $40-50 \%$ ) (Richard and Crossley, 2012).

$$
P=\frac{1}{2} \cdot \rho \cdot A \cdot U^{3} \cdot \eta=\frac{\rho}{2} \cdot \pi \cdot R^{2} \cdot U^{3} \cdot \eta, R=\sqrt{\frac{2 \cdot P}{\rho \cdot \pi \cdot U^{3} \cdot \eta}}=1.95 m
$$




\subsubsection{Rotational Speed of the turbine and Relative wind speed Urel}

As mentioned in table 1, using an optimized tip speed ratio of 7 and wind velocity of $7 \mathrm{~m} / \mathrm{s}$, the rotational speed and the angular speed is calculated using the equations 2 and 3.

$$
\begin{array}{r}
n=\frac{U \cdot \lambda \cdot 60}{2 \cdot \pi \cdot R}=240.4 \mathrm{rpm} \\
\Omega=\frac{2 \pi N}{60}=25.2 \mathrm{rad} / \mathrm{s}
\end{array}
$$

Relative wind speed is the result of wind speed and the rotational wind speed denoted by Urel. The velocities and aerodynamic forces at each cross-section along the blade length are dependent on the relative velocity flowing over the profile of the blade. The relative velocity at each cross-section along the length is given by equation 4 . The results are summarized in table 2 .

$$
U_{r e l}=\sqrt{U^{2}+(\Omega r)^{2}}
$$

\subsubsection{Power at each Cross-sectional Area of the Blade}

The ability of the blade to extract power depends on the position of the blade element from the root of the hub, the area on which the wind flows as shown in figure 2 , and velocity of the wind.

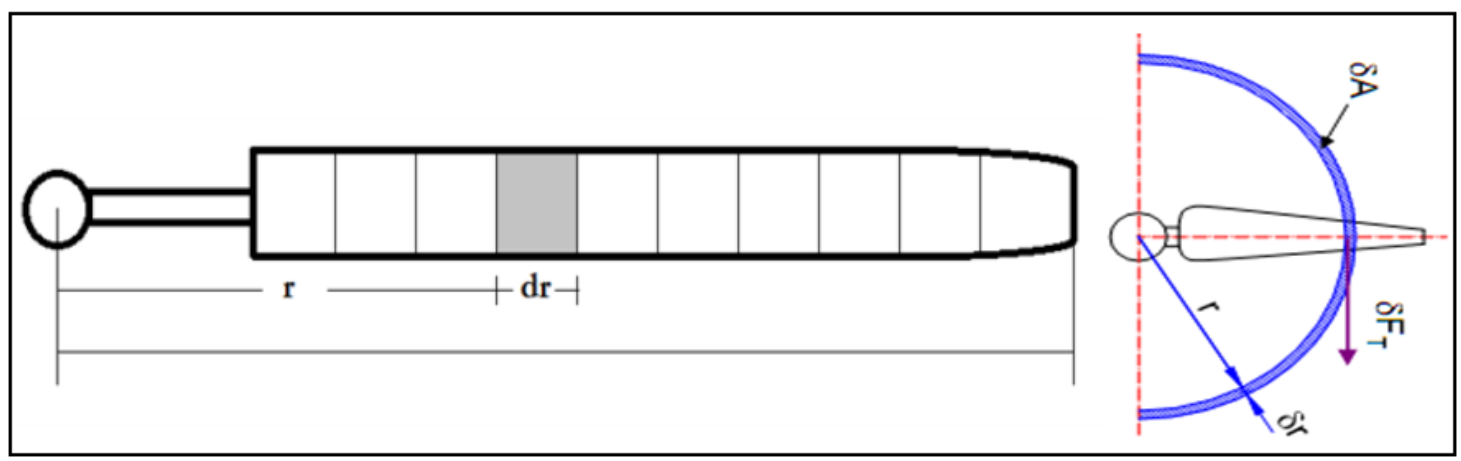

Figure 2. Elemental cross section of the blade along the length.

The expression for the power generated in terms of cross sectional area of air flow is calculated by equations 5 to 7 .

$$
\partial P=\frac{\pi}{2 \times B}\left[(r+\partial r)^{2}-r^{2}\right] \times \rho U^{3} \eta
$$




$$
\partial A=\frac{\pi}{B}\left[(r+\partial r)^{2}-r^{2}\right]
$$

The power output from this blade element is the torque multiplied by the rotational speed. The torque is the force in the rotational direction and it is directly proportional with the radius of the blade length. The expression for the sectional torque in an air flow is given by equation 7 .

$$
\partial P=\partial F_{T} \cdot\left(r+\frac{\partial r}{2}\right) \Omega, \partial F_{T}=\frac{\partial P}{\left(r+\frac{\partial r}{2}\right) \Omega}
$$

\subsubsection{The Lift and Drag Forces}

The force from the blade is determined individually by the lift and drag of the airfoil shape of the blades. Lift and drag force are defined to be perpendicular and parallel to direction of the incoming airflow respectively. The lift and drag coefficients for NACA 64A410 are given in table 1 and equation 8 is used to calculate the lift and drag forces. The results are summarized in table 2.

$$
F_{L}=C_{L} \cdot \frac{1}{2} \cdot \rho \cdot U_{r e l}{ }^{2} \cdot A, F_{D}=C_{D} \cdot \frac{1}{2} \cdot \rho \cdot U_{r e l}{ }^{2} \cdot A
$$

\begin{tabular}{|c|c|c|c|c|c|c|c|c|c|c|}
\hline $\mathbf{r}$ & $\mathbf{r}+\boldsymbol{\delta} \mathbf{r}$ & $\delta \mathrm{A}$ & $\delta P$ & $\delta \mathrm{T}$ & $\delta$ FT & $\Omega r$ & Urel & $\Phi$ & $\mathbf{L}_{\text {Chord }}$ & $\theta$ \\
\hline 0.22 & 0.38 & 0.04 & 8.69 & 0.35 & 1.15 & 9.63 & 11.90 & 36.03 & 0.247 & 31.0 \\
\hline 0.30 & 0.46 & 0.04 & 11.08 & 0.44 & 1.15 & 11.70 & 13.63 & 30.90 & 0.217 & 25.9 \\
\hline 0.46 & 0.63 & 0.03 & 15.85 & 0.63 & 1.15 & 15.84 & 17.32 & 23.84 & 0.173 & 18.8 \\
\hline 0.63 & 0.79 & 0.02 & 20.62 & 0.82 & 1.15 & 19.99 & 21.18 & 19.30 & 0.143 & 14.3 \\
\hline 0.79 & 0.96 & 0.02 & 25.39 & 1.01 & 1.15 & 24.13 & 25.13 & 16.18 & 0.122 & 11.2 \\
\hline 0.96 & 1.12 & 0.02 & 30.16 & 1.20 & 1.15 & 28.28 & 29.13 & 13.90 & 0.107 & 8.9 \\
\hline \begin{tabular}{|l|}
1.12 \\
\end{tabular} & 1.29 & 0.02 & 34.93 & 1.39 & 1.15 & 32.42 & 33.17 & 12.18 & 0.094 & 7.2 \\
\hline \begin{tabular}{|l|}
1.29 \\
\end{tabular} & 1.45 & 0.01 & 39.70 & 1.58 & 1.15 & 36.57 & 37.23 & 10.84 & 0.085 & 5.8 \\
\hline 1.45 & 1.62 & 0.01 & 44.47 & 1.77 & 1.15 & 40.71 & 41.31 & 9.76 & 0.077 & 4.8 \\
\hline 1.62 & 1.78 & 0.01 & 49.24 & 1.96 & 1.15 & 44.86 & 45.40 & 8.87 & 0.070 & 3.9 \\
\hline 1.78 & 1.95 & 0.01 & 54.01 & 2.15 & 1.15 & 49.00 & 49.50 & 8.13 & 0.064 & \begin{tabular}{|l|}
3.1 \\
\end{tabular} \\
\hline 1.86 & 2.03 & 0.01 & 56.39 & 2.24 & 1.15 & 51.07 & 51.55 & 7.80 & 0.062 & 2.8 \\
\hline \multicolumn{3}{|c|}{ Power in each Blade (W) } & 390.50 & & & & & & & \\
\hline \multicolumn{3}{|c|}{ Total Power (W) } & 1171.5 & & & & & & & \\
\hline
\end{tabular}

Table 2. Final blade design geometry.

\subsubsection{Chord Length}

Chord length is the length of the chord line, or the length of the airfoil that spans from the leading to the trailing edge of the blade. Having obtained the expressions for the forces on each element, 
now the thrust force and the chord length can be calculated by equations 9 to 11 . The thrust force coefficient is in axial direction.

$$
\begin{aligned}
& F_{T}=F_{L} \cdot \sin \Phi-F_{D} \cdot \cos \Phi \\
& F_{T}=\frac{\rho}{2} \cdot L_{\text {Chord }} \cdot \partial r \cdot U_{r e l}^{2} \cdot\left(C_{L} \cdot \sin \Phi-C_{D} \cdot \cos \Phi\right) \\
& L_{\text {Chord }}=\frac{2 \cdot F_{T}}{\rho \cdot \partial r \cdot U_{r e l}^{2} \cdot\left(C_{L} \cdot \sin \Phi-C_{D} \cdot \cos \Phi\right)}
\end{aligned}
$$

\subsubsection{Flow Angle}

Flow angle is defined to be the angle between the relative flow velocity and the plane on which the blade is rotating (see Fig 1). The flow angle is computed as a function of the rotational speed, location of the blade element, and incoming wind speed by equations 12 and 13.

$$
\begin{aligned}
& \operatorname{Tan}(\Phi)=\frac{U}{\Omega \cdot r}=\frac{U}{\Omega \cdot\left(r+\frac{\delta r}{2}\right)} \\
& \Phi=\tan ^{-1}\left(\frac{U}{\Omega \cdot\left(r+\frac{\delta r}{2}\right)}\right)
\end{aligned}
$$

\subsection{Blade 3D Modeling}

To help the production of the mold, a 3D modeling of the wind turbine blade is generated using SolidWorks. The first step is importing the airfoil data (see Table 1 and 2) to SolidWorks. This data include the points that describe airfoil coordinate and its chord length. Importing the blade airfoil, the blade elements are aligned at an axis running through the same point in the airfoil. This point is usually near the force center of the airfoil (Fig 3), which is found at about $25 \%$ of the chord length from the leading edge.

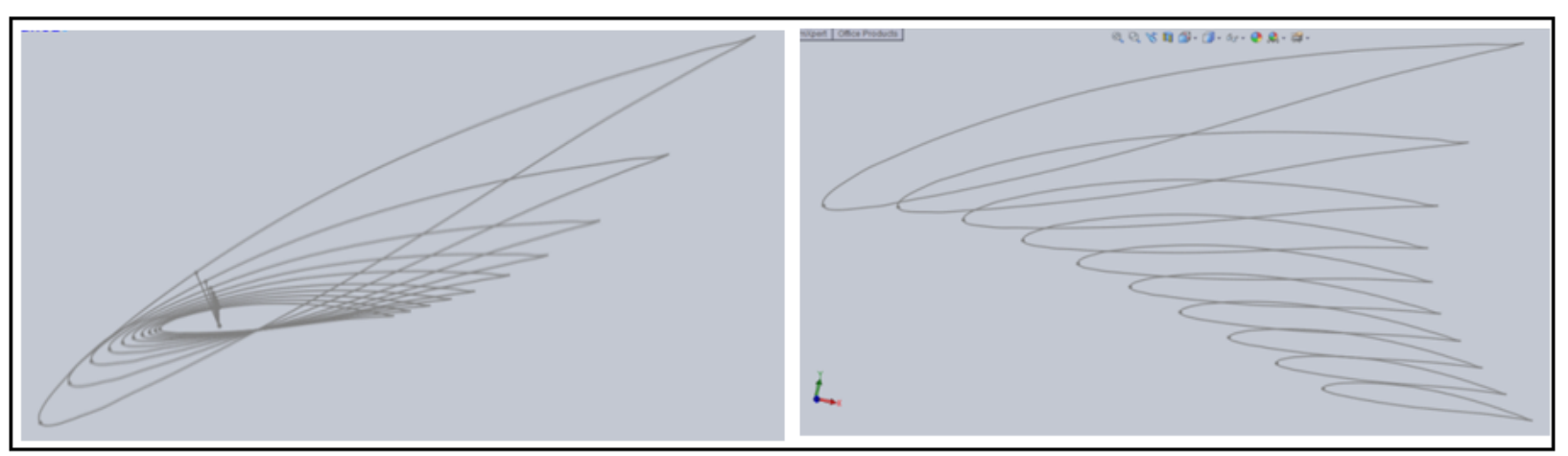

Figure 3. Curves from the front and isometric view using SolidWorks. 
The next step is to use the loft feature in SolidWork to create the geometry of blade, selection of right points in the different airfoils is critical for the loft to be successful (see Fig 4).

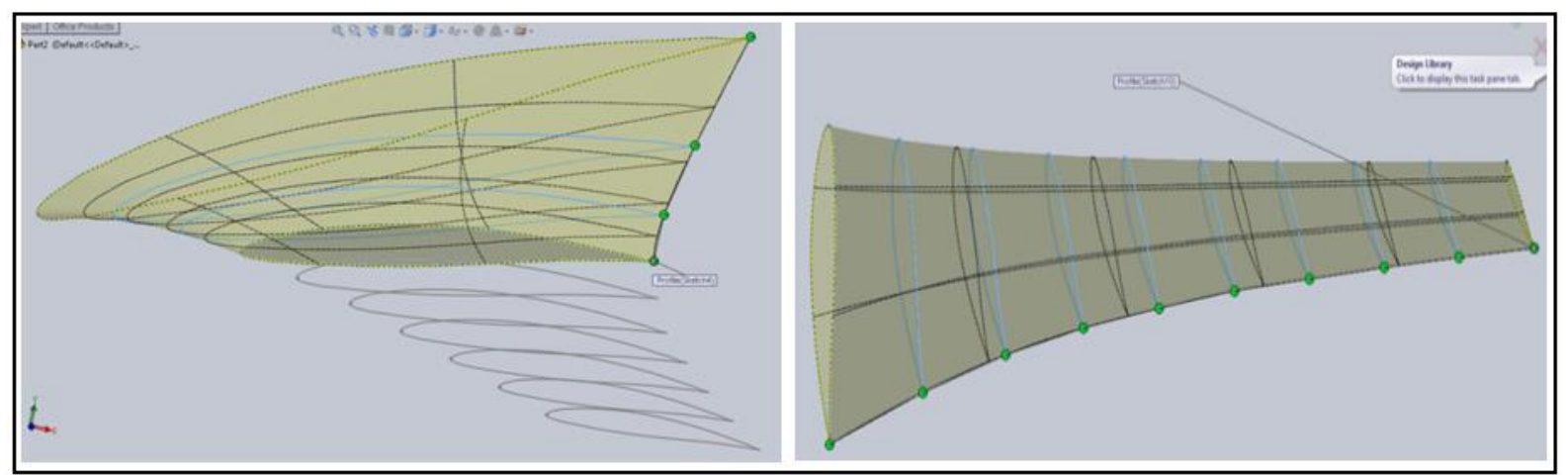

Figure 4. Generating lofts of curves in SolidWorks.

The SolidWork model that showed the simplified geometry of the wind turbine blade with its roots mounted in the hub are depicted in figures 5 and 6 . These are used a guide for the actual manufacturing of the wind turbine blades.

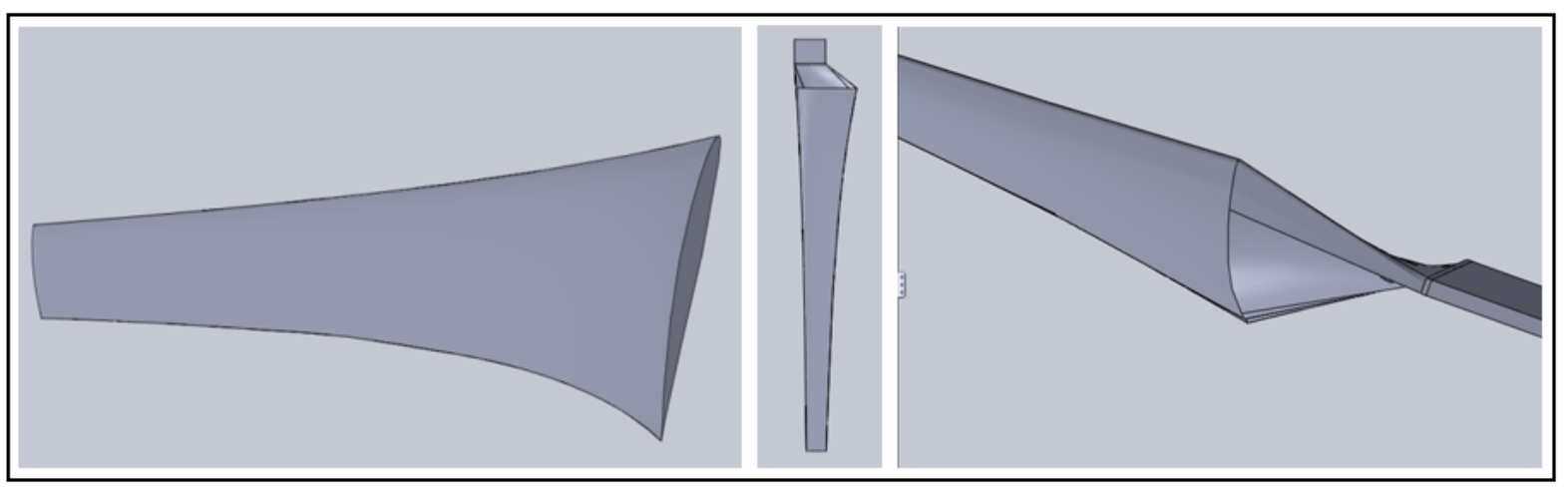

Figure 5. Finalized blade geometry without and with root.

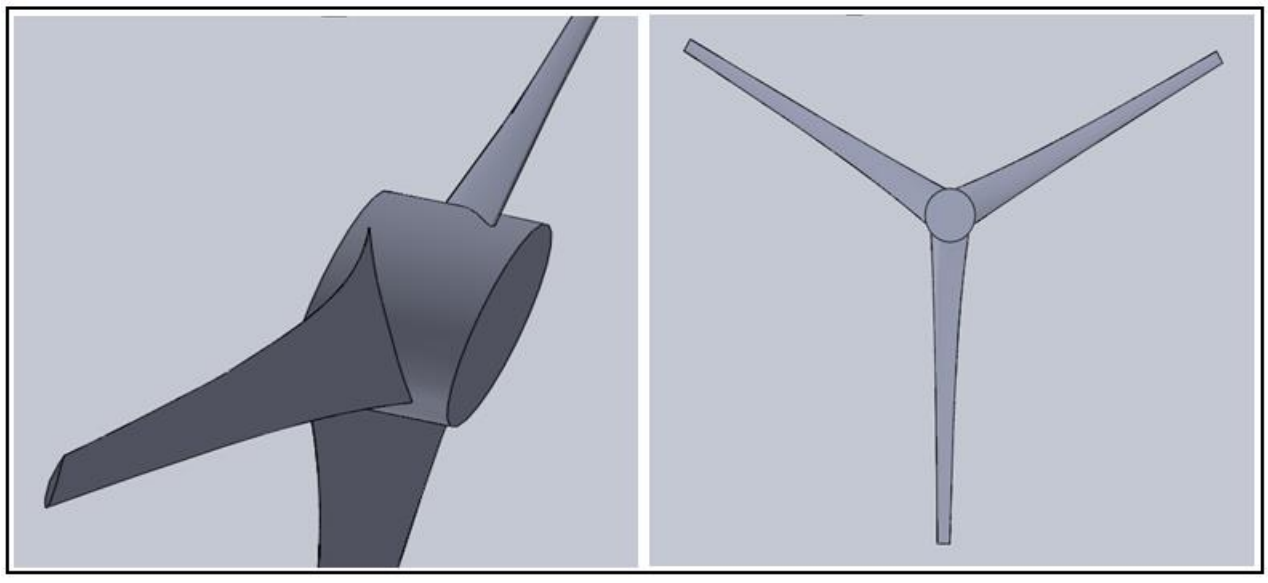

Figure 6. Blade mounted on the hub. 


\section{MANUFACTURING OF ROTOR BLADE}

The method of manufacturing of the wind turbine blade consists of two stages; namely the manufacturing of the mold and manufacturing of the blades. In the earlier stages, the aerodynamic study and rotor blade design was conducted for local condition. And the wind turbine consists of 3 blades at an optimal tip speed ratio of 7 and wind speed of $7 \mathrm{~m} / \mathrm{s}$. Under this condition, the power output of generator is designed to be $1 \mathrm{~kW}$. The blade length is $1.95 \mathrm{~m}$ including the root and the overall features are shown in figure 7. Furthermore, NACA64A410 airfoil was analyzed and the basic output parameters such as chord length and twist angle distribution along the blade length is shown in tables 1 and 2 .

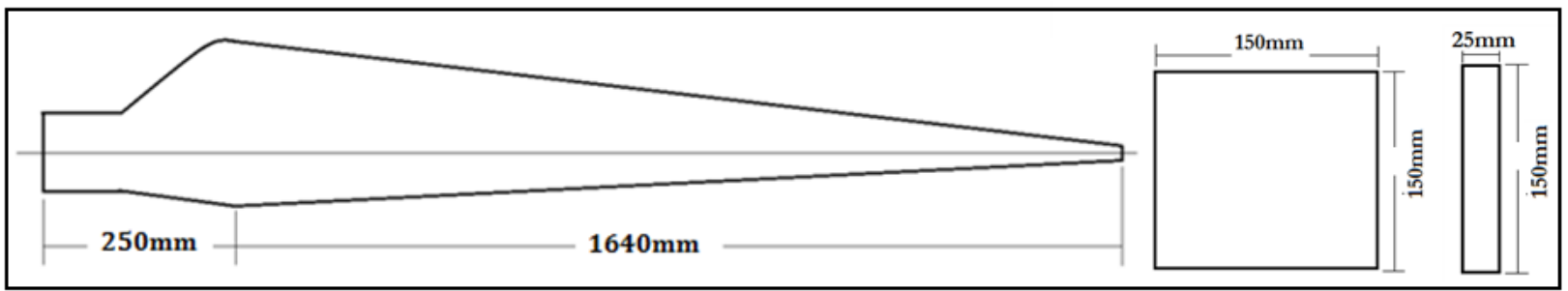

Figure 7. Final blade design geometry root sectional view.

The quality of the final blade output will depend on imprinting the exact shape of the blade characterized by the chord length that creates tapering of the blade from root to tip and the angle of twist that enables the blade to face the relative velocity at an optimum angle. The blade is divided in to 12 sections and chord length and twist angle at each section are given in table 3.

Table 3. Final blade design parameters (such as chord length and twist angle distribution along the blade length).

\begin{tabular}{|ccccc|}
\hline Section & $\boldsymbol{R}$ & $\boldsymbol{r}+\boldsymbol{\delta} \boldsymbol{r}$ & $\boldsymbol{L}_{\text {Chord }}$ & $\boldsymbol{\theta}$ \\
\hline 1. & 0.22 & 0.38 & 0.247 & 31.0 \\
\hline 2. & 0.30 & 0.46 & 0.217 & 25.9 \\
\hline 3. & 0.46 & 0.63 & 0.173 & 18.8 \\
\hline 4. & 0.63 & 0.79 & 0.143 & 14.3 \\
\hline 5. & 0.79 & 0.96 & 0.122 & 11.2 \\
\hline 6. & 0.96 & 1.12 & 0.107 & 8.9 \\
\hline 7. & 1.12 & 1.29 & 0.094 & 7.2 \\
\hline 8. & 1.29 & 1.45 & 0.085 & 5.8 \\
\hline 9. & 1.45 & 1.62 & 0.077 & 4.8 \\
\hline 10. & 1.62 & 1.78 & 0.070 & 3.9 \\
\hline 11. & 1.78 & 1.95 & 0.064 & 3.1 \\
\hline 12. & 1.86 & 2.03 & 0.062 & 2.8 \\
\hline
\end{tabular}




\subsection{Manufacturing of Mold}

The mold made from assembly of wooden templates representing twelve cross-sections along the length of the wind turbine blade, consists of two parts: upper half and lower half. To keep perfect alignment of the airfoil shape, the mold is strengthened by rectangular wooden frames (Habali and Saleh, 2000).

The production process is as follows:

i. The airfoil shapes of the NACA64A410 were first printed on a paper then the shape is traced in a 9mm thick plywood templates. The airfoil shapes are inscribed at their respective position as a function of the twist angle and blade chord length see figure 8 .

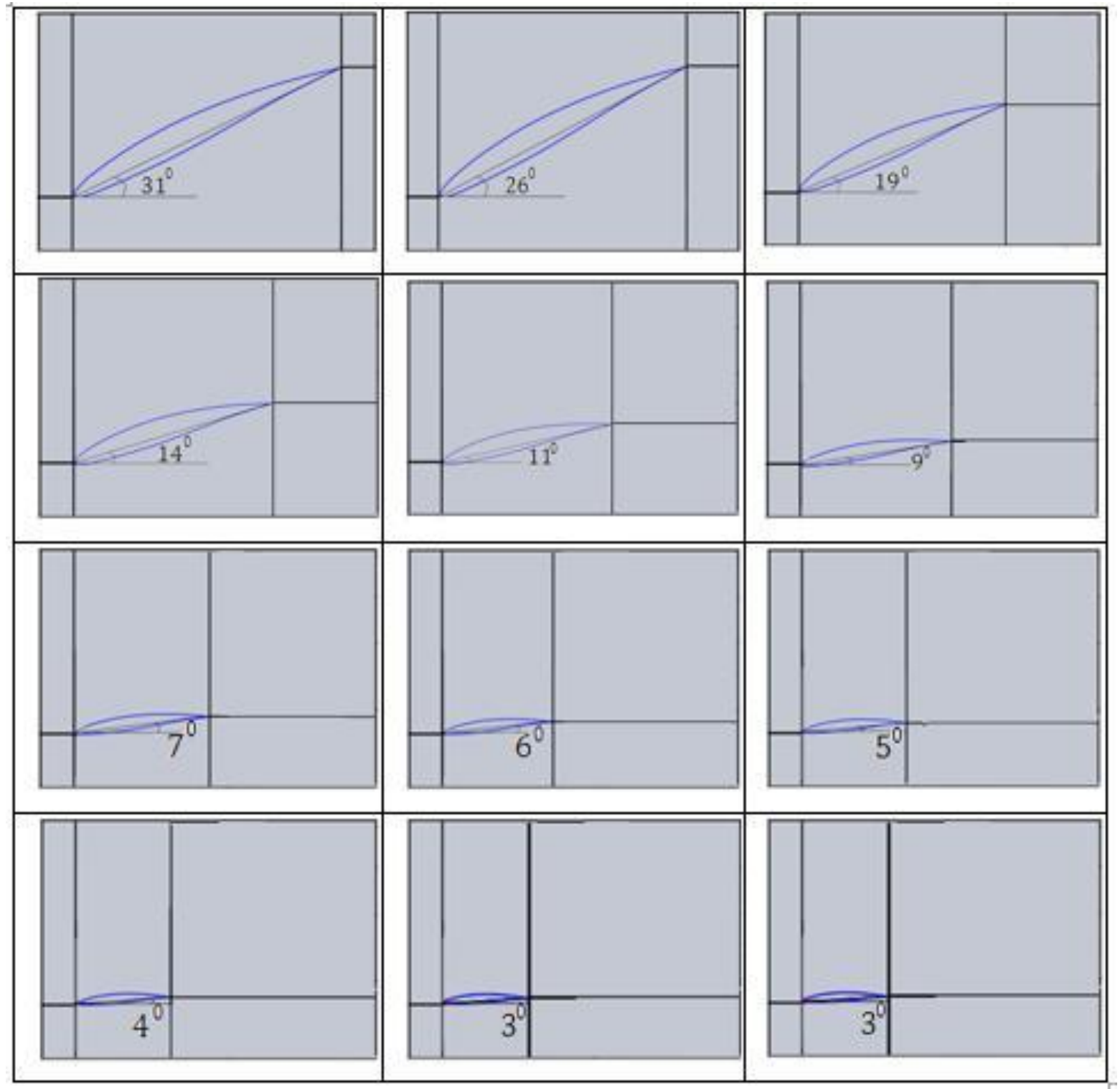

Figure 8. Airfoil shapes in A4 paper ready to be scribed in to the wooden templates. 
For ease of manufacturing, the length of the turbine blade is divided in to twelve crosssections of approximately $164 \mathrm{~mm}$ length. The plywood templates are all identical having a dimension of $315 \mathrm{~mm}$ by $210 \mathrm{~mm}$. Each of the twelve cross-sectional shapes of the wind turbine blade and representative wooden templates are shown in figure 9.

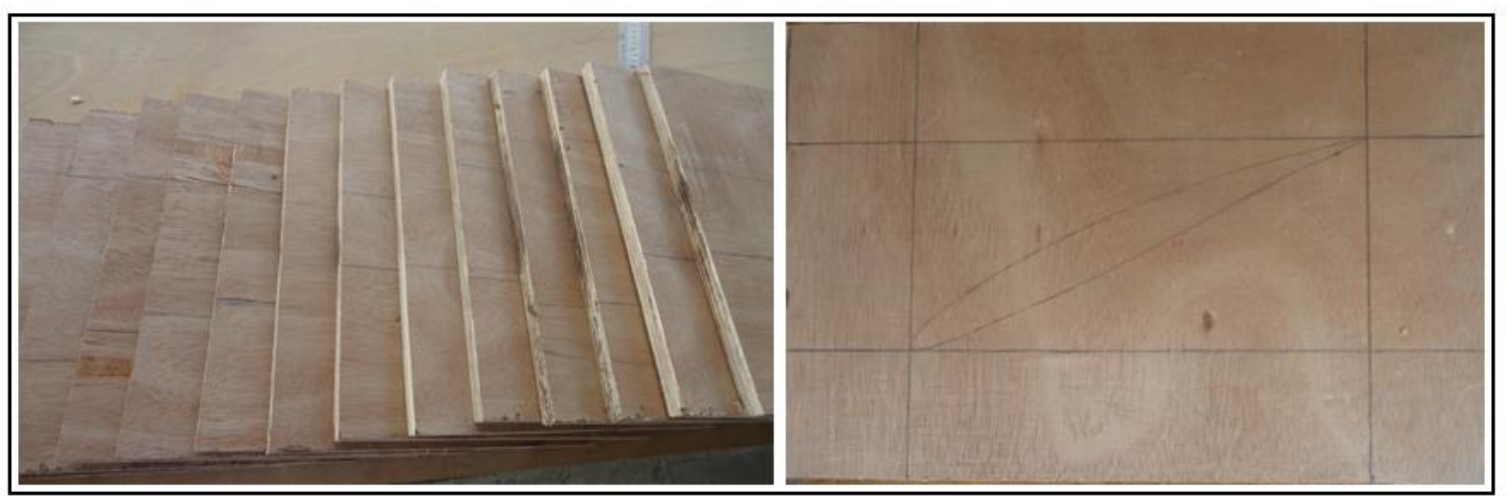

Figure 9. Twelve wooden templates made of plywood of $9 \mathrm{~mm}$ thickness.

ii. The airfoil shapes are carefully removed from the template and polished to assume desired shape of the NACA64A410 series using drill machine and portable handsaw (Fig 10).

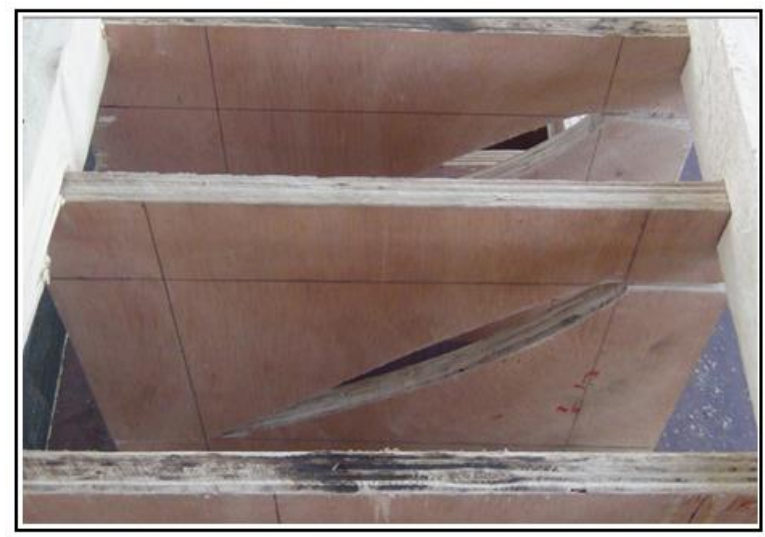

Figure 10. The two elements of the mold (upper and lower halves of the mold).

iii. The twelve airfoil shapes inscribed in the template are stack next to each other sequentially as shown in figure 11. The templates are held in place by a rectangular wooden frame (reinforcement $0.04 \times 0.2 \times 2 \mathrm{~m}$ ) to give the overall structure of the mold. The twist of the blade is included along the length of the mold with their respective angles of twist. 


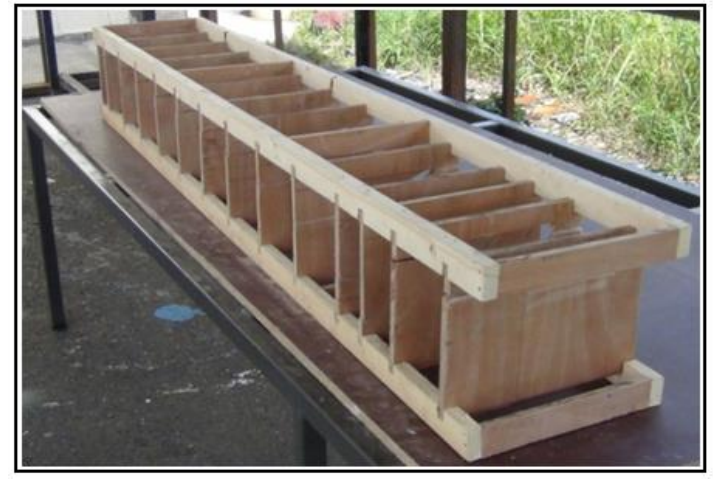

Figure 11. Wind turbine blade mold (templates fixed in their respective position).

iv. The overall structure of the mold is cut in to upper and lowers half sections. Figure 12 shows the upper and lower cross sections of the mold.

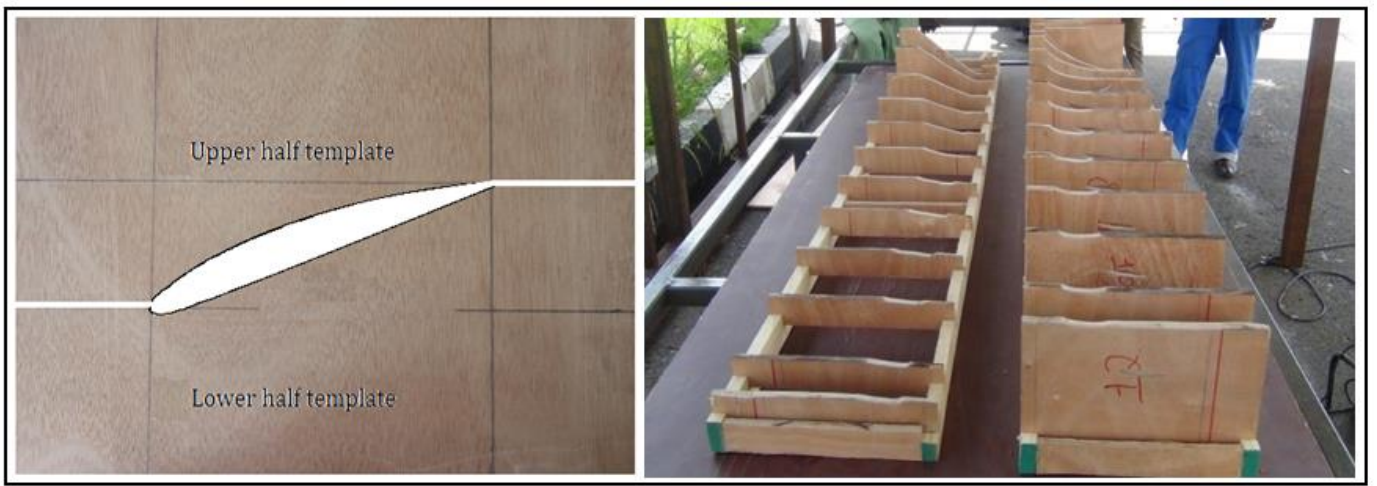

Figure 12. Upper and lower halves of the mold.

v. Finally, the two halves of the mold were laminated with thin film of fiberglass and resign are shown in figure 13.

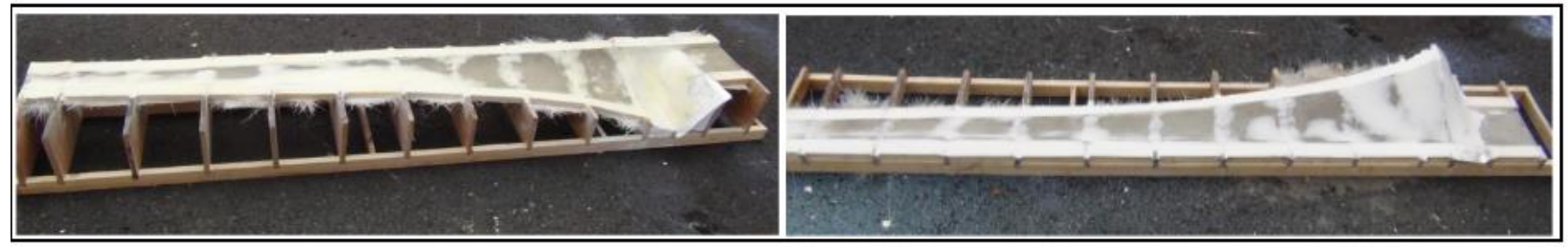

Figure 13. Complete mold with thin film of fiberglass.

\subsection{Manufacturing of Blades}

The turbine blade is made of two halves of independently made fiberglass structures in their respective molds. Then the two halves are joined using resin and one layer of fiberglass as glue 
and kept in position by a c-clamp. The material used for the wind turbine blade manufacture was fiberglass with resin and other ingredients (Matthew and Andrew, 2008; Prombut, 2010).

Given the local radius, chord length and blade angle at each station, it has been possible to fabricate the shape of the whole blade. The root of the blade is flat and rectangular to make the assembly with the hub suitable

Steps in preparing the blade;

i. The molds were cleaned before using.

ii. Wax (release agent) is applied to the molds to ensure that the item produced does not stick to the molds. And in order to facilitate the blade separation from the molds when it is ready.

iii. Gelcoat is painted before resin so that the fiberglass layer will have a smooth finish during removal from the molds. Furthermore, it adds a color to the upper part of the blade.

iv. After painting gelcoat, thin layer of resin was painted in each side of the molds, then a layer of fiberglass. Again a layer of resin on top of the fiberglass. This fiberglass was five layers with approximate $4 \mathrm{~mm}$ thickness as shown in figure 14 .

The material used for the wind turbine blade

- Fiberglass called mat350g is the material used to manufacture the blade. This glass fiberglass is easy to work with as its orientation does not matter. That means the orientation is random and it has the same strength in every direction

- Resin is used to make the fiberglass rigid. The resin is mix with thinner to reduce its viscosity.

- Catalyst is added to the resin mix to start the solidification process. Once the catalyst is added to the resin, it must be laminated quickly into the fiberglass as the resin will solidify quickly.

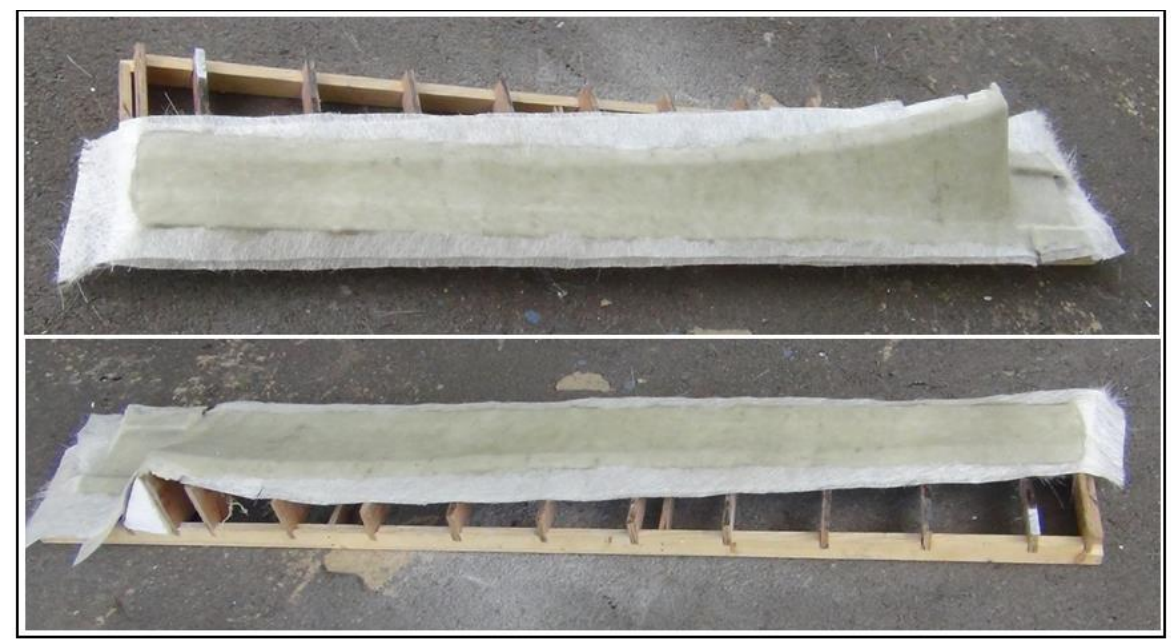

Figure 14. Layers of fiberglass and resin placed to make the two shells of blade. 
i. Once the $4 \mathrm{~mm}$ of fiberglass have been placed each side of the molds and left to stay for 2 hours to dry. The next step was to join the halves and tie them together with a c-clamp. The two halves were joined using resin and one layer of fiberglass as glue.

ii. At the root end of the blade a piece of wood has been added to increase the strength and ultimately reduce the quantity of fiberglass and resin. In addition to increase the strength of the turbine blade, a spar has been added at the center hole of the two halves.

iii. Finally, after joining the two pieces of the molds, it was necessary to leave the mold to stay overnight to dry.

iv. The excess materials during overlapping of the two halves of the blade are cut off using cutter disc and remove the unwanted parts using grinder disc. Care was taken not to remove part of final blade.

v. Now that the blade structure is finished, the next step was smoothing and painting. This step involved filling small holes and gaps by filling stucco as shown in figure 15. Sand papers have also been used to smoothen the surface to a high quality.

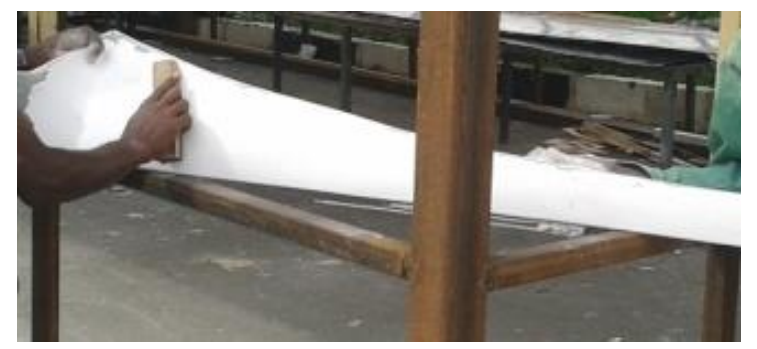

Figure 15. Filling the holes and smoothing the wind turbine blade.

vi. The blades were completed and drilling of the root proceeded to provide attachment to the hub of a generator.

vii. Painting of the blade is the last step with KADILAC N.C. PRIMER, Jet TINTA PRONTA and KADILAC N.C. PUTTY. A compressed air is used to uniformly paint the blades (Fig 16).

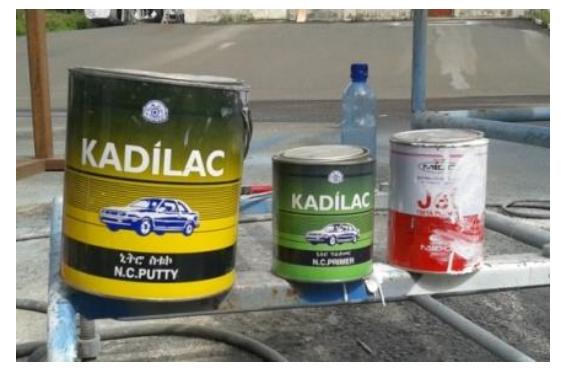

Figure 16. Painting of the wind turbine blade. 
viii. Manufactured three wind turbine blades were ready for test (Fig 17).

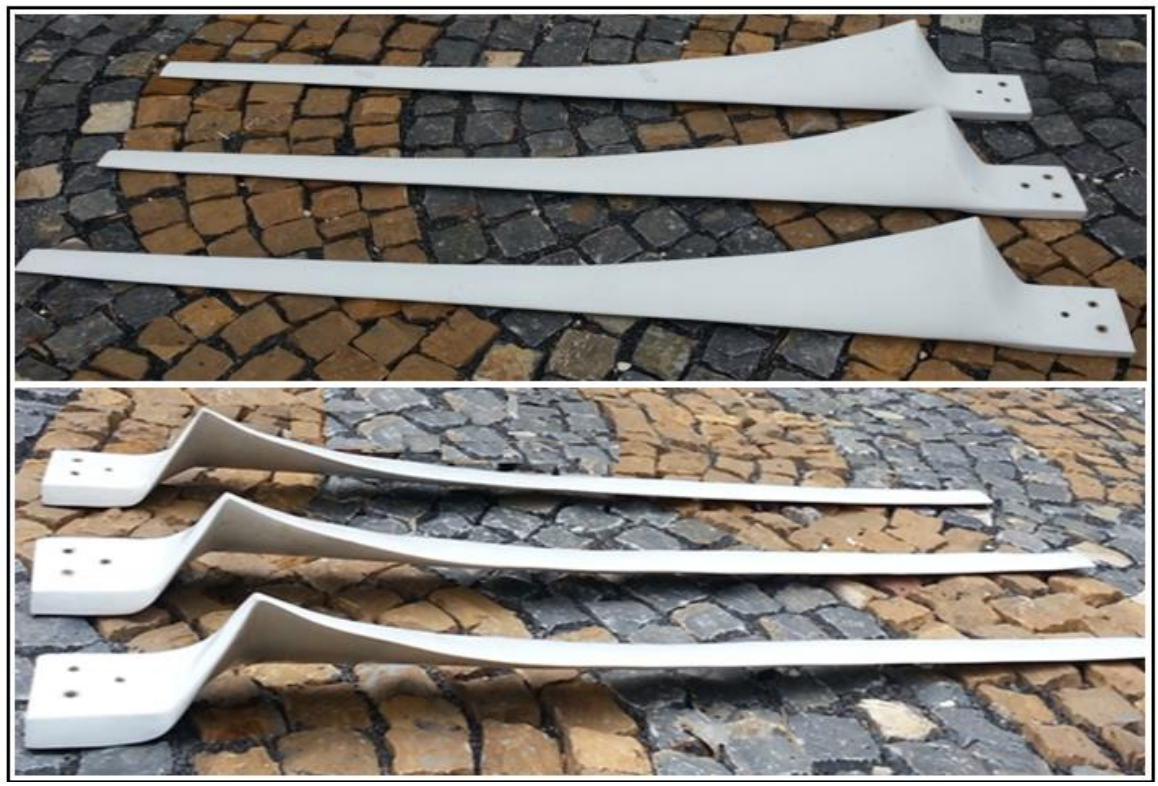

Figure 17. Final full scale wind turbine blade.

ix. Finally, for the overall set up and installation of the wind turbine blade (Fig 18).

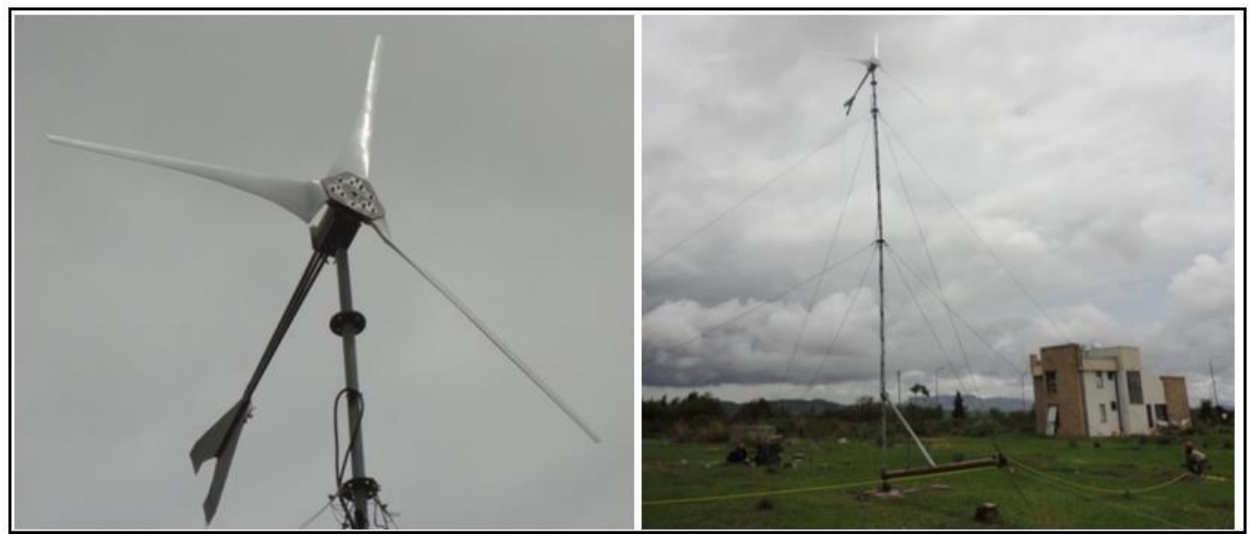

Figure 18. The overall setup of the wind turbine and control room.

\section{RESULTS AND DISCUSSION}

\subsection{Blade Design and Manufacture}

The $1 \mathrm{~kW}$ wind turbine blades were designed and manufactured using the most widely used NACA 64A410 airfoil of the NACA 6-series airfoil. Because the geometrical shape of the wind turbine blade is directly linked to many aspects of the performance of the blade (Eric et al., 2014), analysis on the main parameters resulted in a blade radius of $1.95 \mathrm{~m}$, an overall twist angle of $31^{\circ}$, a 
gradually tapering chord length of $0.062 \mathrm{~m}$ at the root and $0.247 \mathrm{~m}$ at the tip of the blade. In addition to the comprehensive analysis of the design of the blades, we have manufactured the wind turbine blades from fiberglass called mat350g and other ingredients such as resin, catalyst and gelcoat for finishing. First the molds (upper and lower sections) were prepared from a twelve uniformly spaced templates assembled to form the actual shape of the blades. Then the fiberglass mat is laid on the mold and consolidated with resign to get the final blade shape. The results demonstrated a successful design and manufacture of wind turbine blades.

\subsection{Performance Test}

As comprehensive performance testing of the wind turbine blade was beyond the scope of this paper, preliminary testing was conducted to give insight in the power generation. The performance testing of the wind turbine blade was conducted near the meteorological station of Mekelle University. Wind data for the comparison of the power generated by the wind turbine is taken from the wind mast of height $10 \mathrm{~m}$ at the meteorological station. The wind turbine is installed at a wind mast of height $12 \mathrm{~m}$ and a preliminary testing setup was arranged near the wind turbine at the control room. The main parameters measured during the testing process were the wind speed and power generated by the wind turbine.

The power generated against the wind speed at hub height of $12 \mathrm{~m}$ is shown in figure 19 . The power output graph shows that the blades started producing power at a cut-in wind speed of $3 \mathrm{~m} / \mathrm{s}$. The result is in line with previous studies on design and experimental verification of small scale wind turbine blades (Kishore et al., 2013) which showed the cut-in speed of in the range of $3 \mathrm{~m} / \mathrm{s}$. The fitted cure in figure 19 demonstrates that the power generation from the blades is consistent with the theoretical power output of the blades as presented in figure 20. The maximum power achieved during the testing process was approximately $900 \mathrm{~W}$ at wind speed of $9 \mathrm{~m} / \mathrm{s}$. This was due to the fact that the wind flow during field testing did not exceed $10 \mathrm{~m} / \mathrm{s}$ and further testing at high speed was not possible. The efficiency of the wind turbine blade is highly dependent on the manufacturing process. During testing, the actual power output from the wind turbine testing was lower than the expected theoretical power output. These results are mainly attributed to the limitation in the workmanship during the manufacturing process. Similar studies have reported that the quality of blade manufacture which affects the performance of the blades is not only 
dependent on the type of material used but also on the consistency fiber surface treatment and manufacturing process (Prabhakaran et al., 2011).

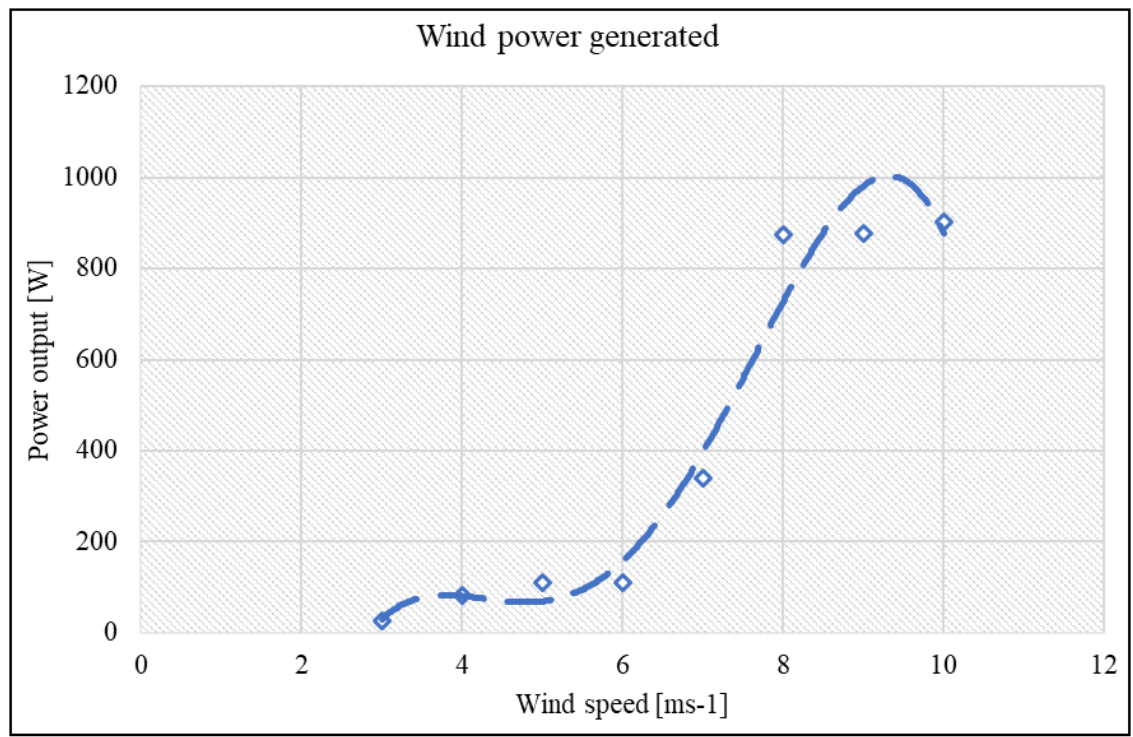

Figure 19. Power generated against wind at the hub height.

The theoretical power output from a wind turbine is a cubic function of the wind speed. At the rated wind speed, however, the power output is kept constant to prevent damage to the wind turbine generator. Comparison of the theoretical and actual power output of the turbine shown in figure 20 reveals that the power output from the wind turbine is close to the theoretical output.

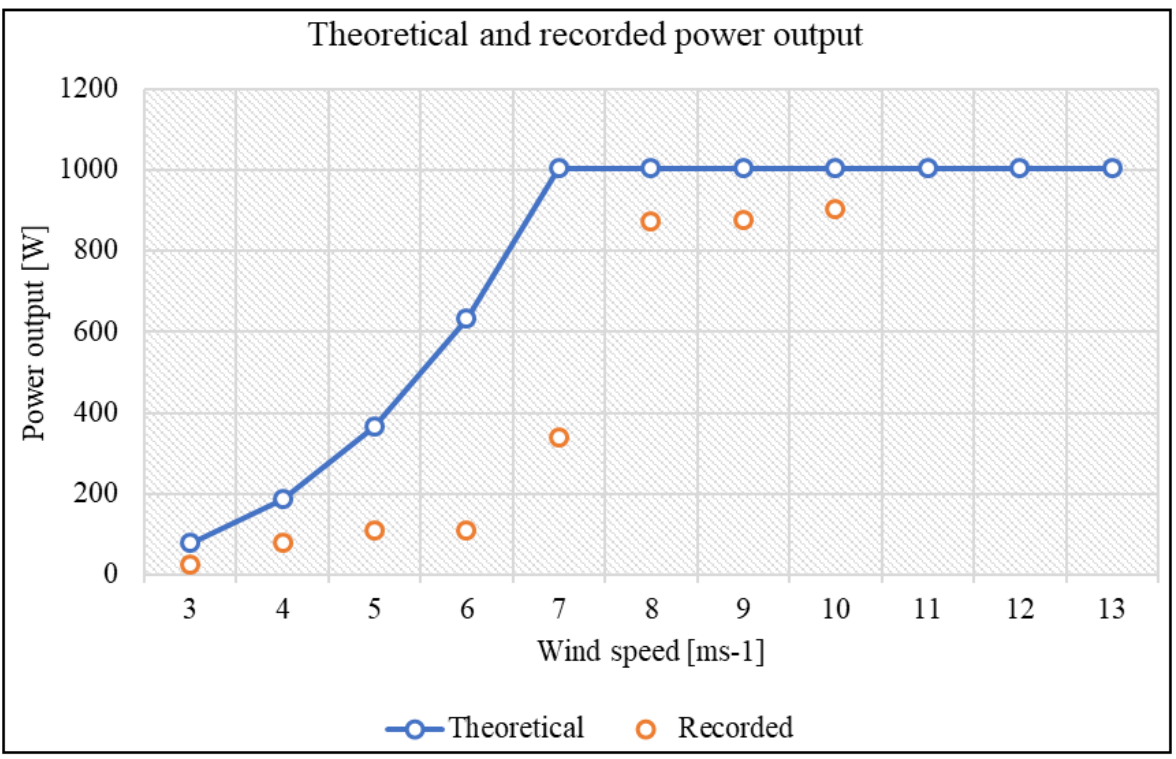

Figure 20. Theoretical and recorded power output curves. 
The coefficient of performance (the actual power output against the theoretical power output) is expected to gradually increase until the rated power output of the turbine and then gradually decrease. From this study, a maximum coefficient of performance of 0.23 which is in good agreement with similar studies of small scale wind turbine blades (Suresh and Rajakumar, 2020; Kishore et al., 2013)

\section{CONCLUSIONS AND RECOMMENDATIONS}

To meet the rising demands for renewable energy and off-grid applications, a $1 \mathrm{~kW}$ wind turbine blade is locally designed, manufactured and tested in Mekelle University Ethiopia. The process of design and manufacture of the wind turbine blade went through the selecting of appropriate materials, proper sizing of the detail geometry, and manufacturing process. The material used to manufacture the blade was fiberglass called mat350g with resin and other ingredients to facilitate quality product. The final blade tapered in shape has a length of $1.95 \mathrm{~m}$. The process of manufacturing the wind turbine blade was made aerodynamically suitable for actual wind conditions.

The practical testing of the wind turbine blades has proven successful. Experimental results demonstrate that the wind turbine is capable of producing $900 \mathrm{~W}$ power at an average velocity of $9 \mathrm{~m} / \mathrm{s}$. The $1 \mathrm{~kW}$ wind turbine blade can be used for small scale applications and other purposes that require energy where there is no electric grid. It can also be a way forward to the production of large scale wind turbines.

The performance of the wind turbine blade is highly influenced by several factors including the manufacturing process, the surface finish of the desired airfoil, and testing facilities, hence further research might explore optimization in the different variables. It is recommended that other locally available materials and airfoil profiles be studied thoroughly. To fully understand the mechanical behavior and performance of the wind turbine blades, further investigation should be performed both on laboratory and field tests to establish greater accuracy.

\section{ACKNOWLEDGMENTS}

We acknowledge funding provided for the research by EnPe program under EiT-M, Mekelle University. The authors are grateful to Metal and Engineering Corporation of Degen Aviation Industries in Ethiopia for providing us with all the necessary resources to manufacture the wind 
turbine blade and thanks to the employees of the industry for their tireless help and for supportive ideas.

\section{CONFLICT OF INTERESTS}

No conflict of interests.

\section{REFERENCE}

Afanador, A., Koper, M \& Teferra, M. 2016. Off-grid Rural Electrification in Ethiopia. NAMA Developed within the Mitigation Momentum Project.

ARE. 2012. The Potential of Small and Medium Wind energy in Developing Countries: A Guide for Energy Sector Decision-Makers. Retrieved from https://www.ruralelec.org

Dalelo, A. 2003. Rural Electrification in Ethiopia: Opportunities and Bottlenecks. Center for Development and Research Bon University, 13.

Erick, Y., Jorge, A., Alan Jimenez, R., Victor López, G \& Jesus Villalon, L. 2014. Design and Manufacturing of Wind Turbine Blades of Low Capacity Using Cad/Cam Techniques and Composite Materials. Energy Procedia, 57: 682-690 (doi:10.1016/j.egypro.2014.10.223).

Foster, R. 2011. Small Wind Turbines May Change the Future of Energy in Developing Countries. Trade, Investment, and Sustainable Development, 11(3): 27-28.

Habali, S. M \& Saleh, I. A. 2000. Local Design, Testing and Manufacturing of Small Mixed Airfoil Wind Turbine Blades of Glass Fiber Reinforced Plastics: Part II: Manufacturing of the Blade and Rotor. Energy Conversion and Management, 41(3): 281-298 (doi.org/10.1016/S0196-8904(99)00104-1).

Hansen, M. O. L. 2017. Aerodynamics and Design of Horizontal-Axis Wind Turbines. In: T. M. Letcher (Ed.), Wind Energy Engineering (pp. 161-184). https://doi.org/10.1016/B978-012-809451-8.00009-6.

Hau, E. 2006. Wind Turbines: Fundamental, Technologies, Application, Economics. $2^{\text {nd }}$ Edition, Springer, 783p (doi: 10.1007/3-540-29284-5).

Ingram, G. 2011. Wind Turbine Blade Analysis using the Blade Element Momentum Method. Version 1.1. 21p (http://creativecommons.org/licenses/by-sa/3.0/). 
Keho, Y. 2016. What Drives Energy Consumption in Developing Countries? The Experience of Selected African Countries. Energy Policy, 91: 233-246. (doi.org/10.1016/j.enpol.2016.01.010)

Kishore, R.A., Coudron, T \& Priya, S. 2013. Design and experimental verification of a high efficiency small wind energy portable turbine (SWEPT). Journal of Wind Engineering and Industrial Aerodynamics, 118: 12-19 (doi.org/10.1016/j.jweia.2013.04.009).

Marcus. 2013. Small Wind in a Developing World - Renewable Energy Focus. Retrieved April 9, 2019- www.renewableenergyfocus.com/view/32333/small-wind-in-a-developing-world/

Matthew, L \& Andrew, C. 2008. Fiber Glass Wind Turbine Blade: Manufacturing Guide. Retrieved from http://answers.practicalaction.org/our-resources/item/fiber-glass-windturbine-blade-manufacturing-guide

Mishnaevsky, L., Branner, K., Petersen, H. N., Beauson, J., McGugan, M \& Sørensen, B. F. 2017. Materials for Wind Turbine Blades: An Overview. Materials, 10(11): (https://doi.org/10.3390/ma10111285).

Mohammadi, M., Mohammadi, A., Mohammadi, M \& Minaei, H. N. 2015. Optimization of Small Scale Wind Turbine Blades for Low Speed Conditions. Journal of Clean Energy Technologies, 4(2): 140-143 (https://doi.org/10.7763/JOCET.2016.V4.268).

Mulugetta, Y. 2008. Human Capacity and Institutional Development Towards a Sustainable Energy Future in Ethiopia. Renewable and Sustainable Energy Reviews, 12(5): 1435-1450 (https://doi.org/10.1016/j.rser.2007.01.007).

NPC. 2016. Growth and Transformation Plan II (GTP II) (2015/16-2019/20). FDRE, National Planning Commission.

Prabhakaran, R. T. D., Andersen, T. L., Bech, J. I \& Lilholt, H. 2011. Thermoplastic composites for future wind turbine blades - Pros and Cons. In $18^{\text {th }}$ International Conference on Composites Materials, ICCM 2011 - Jeju, South Korea, Volume: Aug 21 - 262011.

Prombut, P. 2010. Manufacturing of a Prototype Blade for Small Wind Turbines. 5.

Qurashi, M. M \& Hussain, T. 2005. Renewable Energy Technologies for Developing Countries Now and to 2023. Publications of the Islamic Educational, Scientific and Cultural Organization -ISESCO.

REN21. 2018. Renewables 2018 Global Status Report. Renewable Energy Policy Network for the 21 Century. 
Richard, J \& Crossley, P. J. S. 2012a. Wind Turbine Blade Design. Energies, 5: 3425-3449 (https://doi.org/10.3390/en5093425).

Richard, J \& Crossley, P. J. S. 2012b. Wind Turbine Blade Design Review. Wind Engineering, 36(4): 365-388.

Rolland, S. 2013. Promoting Small Wind in Developing Markets. Retrieved from https://www.renewableenergyworld.com/articles/print/volume-16/issue-2/wind-power/ promoting-small-wind-in-developing-markets.html

Sessarego, M \& Wood, D. 2015. Multi-dimensional optimization of small wind turbine blades. Renewables: Wind, Water, and Solar, 2:9, 11p (doi.org/10.1186/s40807-015-0009-x).

Suresh, A \& Rajakumar, S. 2020. Design of small horizontal axis wind turbine for low wind speed rural applications. Materials today proceedings, 23(1): 16-22

Tangler, J. L \& Somers, D. M. 1995. NREL airfoil families for HAWTs (No. NREL/TP--4427109, 10106095; p. NREL/TP--442-7109, 10106095) (doi.org/10.2172/10106095).

Thumthae, C. 2015. Optimum Blade Profiles for a Variable-Speed Wind Turbine in Low Wind Area. Energy Procedia, (75): 651-657.

Wood, D. 2011. Small Wind Turbines: Analysis, Design, and Application. Springer, 272p (doi: 10.1007/978-1-84996-175-2).

World Bank. 2018. Ethiopia Electrification Program. Retrieved from http://documents.worldbank.org

WWEA. 2017. WWEA released latest Global Small Wind Statistics. Retrieved April 9, 2019, from http://small-wind.org/wwea-released-latest-global-small-wind-statistics/ 